\title{
Taxes of Pareto Optimality in the Externalities of Consumption Pollution --Based on Sustainablity of Renewable Resources
}

\author{
Jun TANG ${ }^{\mathrm{a}, 1}$, Yi WANG ${ }^{\mathrm{b}}$ and Bibo LIANG ${ }^{\mathrm{b}}$ \\ a School of economics, Guangdong Peizheng College, GuangZhou, China \\ b School of economics, Guangdong University of economic and finance, Guangzhou, \\ China
}

\begin{abstract}
Due to the limitation of substitution of artificial resources for natural resources, Whether natural resources are sustainable has become an unavoidable problem in social and economic development. Pollution will lead to the reduction of natural ecological resources, such as fresh air, water and so on. In this paper, we are only consider the pollution issue caused from consumption. Assume we have a perfectly competitive economy. Let the consumption of individuals generate an externality (for concreteness, it will be referred to as smoke) that induce the amount of a nature resources such as fresh air and lead to a decrease in individual utility. this paper discusses how to make the perfectly competitive market subject to sustainable constraint of renewable resources reach Pareto optimality by means of setting consumption pollution tax. under the sustainable condition of regenerated natural resources, consumption tax construct of achieving Pareto optimality in perfect competition market is discussed based on the basic externality model. At present, China has begun to impose environmental tax. The research results provide a reliable theoretical basis for the setting of environmental tax.
\end{abstract}

Keywords. Consumption pollution, externalities, Pareto efficiency, Sustainable Optimal tax rate.

\section{Introduction}

Human's Productivity and consumption has increased rapidly since the industrial revolution. The pollution caused by human consumption exceeds the capacity of the natural ecological environment to absorb it. Public pollution incidents emerge one after another, such as urban air pollution and water pollution. This not only worsens people's the living environment, but also restricts the development of economy. The sustainability of economy and ecological environment has become the main problem of current social and economic development. How to achieve effective of market under the constraints of sustainable ecological resources is an unavoidable practical problem for all countries.

1 Corresponding Author, Jun TANG, School of economics, Guangdong Peizheng College, GuangZhou, China; Email: juntang_77@163.com. 
Economists saw the problem of pollution as externalities of production or consumption. Because there is no "price" that provides the proper incentive for reduction of polluting activities, The accumulation of pollution exceeded the assimilative capacity of the ecological environment. In the long run, this will destroy the ability of the ecological environment to repair itself. Early Marshall and Pigou had already suggested an solution to the problem. Their proposed solution to this problem was to impose a appropriate "price" (or tax) on polluting activities so as to internalize the externalities. Later, different methods were proposed for different pollution situations. For mobile sources of pollution, such as transportation industry, environmental tax is used to lead to behavior of pollution emitters. Today, all EU countries impose taxes on environmental resources. China began to levy an environmental protection tax on January 1, 2018. How to achieve sustainable ecological resources and economic efficiency by levying environmental tax is a problem worth exploring.

In the 1970s, the formal analysis model[1] of externalities was constructed. It mainly discussed that what taxes are necessary to induce firms and individuals to behave in a manner compatible with the requirements for pareto optimality in a perfectly competitive market. The efficiency of the market does not guarantee the sustainability of ecological resources. Pollution and environmental damage will affect the next generation. Owarth, R, B, and R, B. Norgaard(1992) [2] used an overlapping dynamic model to illustrate: Even if the correct valuation of environmental resources is given and the economy reaches the Pareto efficient boundary, the economy is not necessarily sustainable. The capital of the next generation declines over time, And pollution stocks rose.

sustainability of ecological resource and economic efficiency are two separate concepts. It is widely accepted that ecological sustainability is primarily a matter of equity, not efficiency. The general definition of sustainability is that next generations are as well off as their predecessors. it means that there will be no decline in productivity. Neoclassical growth theory incorporates ecological resource constraints into economic activities (Solow,1974)[3] and Implicitly treat sustainability as consumption does declining over time. further It develops into non-decreasing utility. Sustainability means that ecological resources (natural capital) should be maintained unchanged. Hartwick (1977) [4] proposed a rule to test sustainability. In his opinion, contemporary people are endowed with endowment, which is partly composed of natural capital and artificial capital. The sustainability means that the endowment should be kept intact, and only the service flow of endowment should be consumed.

recently, sustainability has been put on the public policy agenda in an attempting to achieve both sustainability and economic efficiency by environmental taxes in china. The setting of environmental tax faces two basic problems: one is the problem of market efficiency; another is the sustainable problem of ecological resources. Most of the studies focus on field of production. This paper discusses the determining of Pareto optimal tax rate for the externality of consumption pollution under constraint condition of sustainable ecological resources. The research used the formal external analysis method. Under the sustainabl condition of ecological resource, we first derive the necessary conditions for pareto optimality. Then we can determine what taxes are necessary to induce individuals to behave in manner compatible with requirements for pareto optimality under the sustainable condition of ecological resource. The conclusion is that under the constraints of sustainablity, Pareto efficiency of the perfectly competitive market can be achieved by imposing a single tax rate. The 
theoretical results are to provide a theoretical basis for the formulation of pollution taxes.

\section{Description of Model}

The production activities of the firms are pollution-free and consumers produce pollution in A perfectly competitive market. Pollution has public externalities. and the level of pollution depends on the total amount of goods consumed. For example, air pollution is caused by consumers using cars. Air pollution is a public good with public externality, and it has the same negative utility for every individual. Part of consumption pollution is absorbed by the ecological environment and will not harm consumers. And the other part that exceeds the assimilative capacity of the environment is accumulated in the natural environment, which cause continuous harm to consumers. In a perfectly competitive market, the firms decides the output under the market price, and the consumer decides to consume the quantity of goods under the market price and consumption taxes.

The model uses the following mathematical notation:

There are $\mathrm{m}$ consumers: $\mathrm{j}=1,2,------, \mathrm{m}$; and There are $\mathrm{h}$ firms: $\mathrm{k}=1,2,---, \mathrm{h}$.

$x_{i j}$ - The amount of good (resource) i consumed by individual $\mathrm{j}, i=1,2, \ldots n ; j=1,2 \ldots m$

$y_{i k}$ - The amount of good (resource) $i$ produced by firm $\mathrm{k}, i=1,2, \ldots n ; k=1,2 \ldots h$

$r_{i}---$ The total quantity of (resource) $i$ available to the community , $i=1,2, \ldots n$.

The resource availability constraints are as follows:

$\sum_{j}^{\mathrm{m}} x_{i j}-\sum_{k}^{\mathrm{h}} y_{i k} \leq r_{i}$

$$
i=1,2 \ldots, \mathrm{n}
$$

$f^{k}\left(y_{1 k}, y_{2 k, \ldots,} y_{n k} \leq 0--\right.$ The production set of firm $k, k=1,2 \ldots h$.

The production function $f^{k}\left(y_{1 k}, y_{2 k}, \ldots, y_{n k}\right)$ of the firm $\mathrm{k}$ is determined by the basic assumptions of production technology. the feasible production set for each firm is a set of technical constraints that are twice differentiable and define convex production possibility set.

$$
S\left(\sum_{i}^{n} \sum_{\mathrm{j}}^{\mathrm{m}} x_{\mathrm{ij}}\right)--- \text { reduction of ecological resources caused by pollution }
$$

The amount of reduction of ecological resources caused by pollution is related to the total amount $\sum_{i}^{n} \sum_{\mathrm{j}}^{\mathrm{m}} x_{\mathrm{ij}}$ of consuming goods. $u^{j}\left(x_{1 j}, x_{2 j}, \ldots, x_{n j}, z\right)---$ The utility function for individual $j, j=1,2 \ldots m$.

$$
x_{i j} \geq 0, i=1,2, \ldots . n ; j=1,2 \ldots . m
$$

Here the variable $\mathrm{z}$ in each utility represents a ecological resource such as clean air or water which can be both regenerated and degraded by contamination. Therefore the utility of the corresponding individual is affected by the externality of contamination.

We assume that the feasible set of consumption complexes for each consumer is convex, closed, bounded form below in the x's, and contains the null vector, that the utility function that represents each person's preference is twice differentiable, quasi-concave, and increasing in the x's. Under these circumstances, as is well-known, 
the solution to the maximization problem that is about to be described exists and is unique.

The change of ecological resources quantity depends on both the amount of regenerative ecological resources and the amount of pollution generated by consumption.

Thus the changes of ecological resources quantity as:

$$
\begin{array}{r}
z-z_{0}=\delta z_{0}-S\left(\sum_{i=1}^{n} \sum_{j=1}^{m} x_{i j}\right) \\
z=(1+\delta) z_{0}-S\left(\sum_{i=1}^{n} \sum_{j=1}^{m} x_{i j}\right)
\end{array}
$$

Where ${ }^{Z 0}$ is the quantity of ecological resources before pollution of consumption. $\delta z 0$ is the regenerated quantity of ecological resources(the service flow of endowment $\left.z^{0}\right) . \delta$ is a constant, which represent the ecological resources will grow at rate $\delta$. The quantity of ecological resources change $z-z_{0}$ depends on the quantity $z_{0}$ of ecological resources before pollution and the regeneration speed $\delta$ of ecological resources, as well as the reduction $S=S\left(\sum_{i}^{n} \sum_{\mathrm{j}}^{\mathrm{m}} x_{\mathrm{ij}}\right)$ of ecological resources caused by pollution. When, $z-z_{0} \geq 0$ i.e. $\delta z_{0} \geq S\left(\sum_{i=1}^{n} \sum_{j=1}^{m} x_{i j}\right)$, the ecological resources do not decrease, therefore, sustainable condition of the ecological resources is:

$$
\delta z_{0} \geq S\left(\sum_{i=1}^{n} \sum_{j=1}^{m} x_{i j}\right)
$$

\section{Pareto Optimal Conditions for Sustainable Condition of Ecological Resources}

Pareto optimality is a state of resource allocation in which it is impossible to make someone's situation better without making anyone worse off. In order to obtain Pareto optimality condition under the condition of ecological resource sustainability, the formal analysis model method of external effects is referred to [5]. Let the utility function of any arbitrarily chosen individual ( say individual 1) be maximized and subject to the requirements that there be no consequent loss to any other individual, and that the constraints constituted by the production functions and the availablility of resources are satisfied and condition of ecological resource sustainability.

The Pareto optimality problem under sustainable condition is to: 


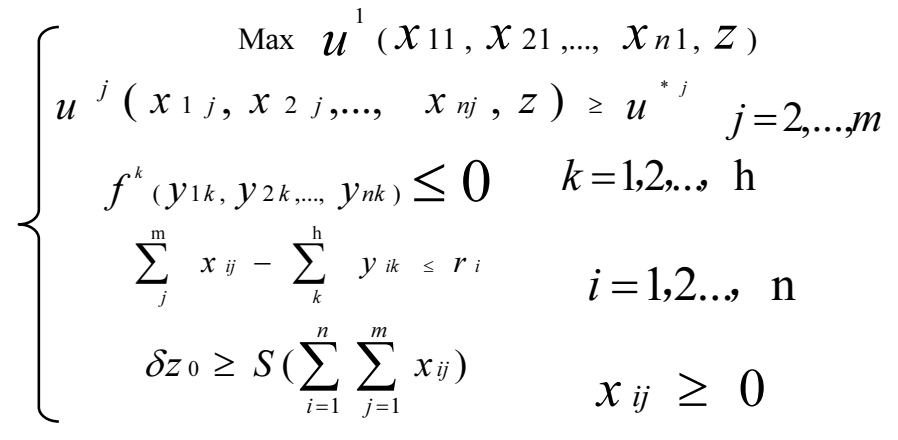

In (4), $\quad$ Reflect the change of ecological resources. compared with the standard formal analysis model[1] of externalities, This model adds conditions for sustainability condition ecological resource: $\delta z_{0} \geq S\left(\sum_{i=1}^{n} \sum_{j=1}^{m} x_{i j}\right)$

Therefore, this model represents the Pareto optimal problem under ecological sustainability. Because of our concavity-convexity assumptions we can use the Kuhn-Tucker theorem to characterize the desired maximum.

Let's do the Lagrangian as follows:

$\mathrm{L}=\sum_{j=1}^{m} \lambda_{j}\left[u^{j}\left(x_{1 j}, x_{2 j}, \ldots, x_{n j}, z\right)-u^{\cdot j}\right]-\sum_{k=1}^{h} \mu_{k} f^{k}()+.\sum_{i=1}^{n} \omega_{i}\left(r_{i}-\sum_{j=1}^{m} x_{i j}-\sum_{k=1}^{h} y_{i k}\right)+\theta\left[\delta z_{0}-S().\right]$

Differentiating in turn with respect to the $x_{i j}, y_{i k}$, we can obtain the Kuhn Tucker condition as follows:

$$
x_{i j} \geq 0 \begin{gathered}
\lambda_{j}\left(\frac{\partial u^{j}}{\partial x_{i j}}+\frac{\partial u^{j}}{\partial z} \frac{\partial z}{\partial x_{i j}}\right)-\omega_{i}-\delta \frac{\partial S(.)}{\partial x_{i j}} \leq 0 \\
x_{i j}\left[\lambda j\left(\frac{\partial u^{j}}{\partial x_{i j}}+\frac{\partial u^{j}}{\partial z} \frac{\partial z}{\partial x_{i j}}\right)-\omega_{i}-\delta \frac{\partial S(.)}{\partial x_{i j}}\right]=0 \\
-\mu_{k} \frac{\partial f^{k}}{\partial y_{i k}}+\omega_{i} \leq 0
\end{gathered}
$$

\section{Market Equilibrium Condition Under Consumption Taxes}

We consider first the corresponding to market equilibrium requirements. Specifically, our objective is to determine the characteristics of the taxes, assuming that they exist, that will induce the behavior patterns necessary (and sufficient) for the satisfaction of our Pareto-optimality condition.

Because pollution is produced by consumption, we impose on goods which is consumed by each individual a tax rate, per unit goods for $t$ whose value is determined.

Suppose that the tax on consumption of unit commodity $i$ be ti(i=1,2,..,n). equilibrium of consumer and of firm in perfect competitive market is discussed as follow. The consumer is taken to minimize the expenditure necessary to achieve any 
given level of utility $u^{* j}$, so that in Lagrangian from the problem is to find the saddle value of

$$
\mathrm{L}_{\mathrm{j}}=\sum_{i=1}^{n}\left(p_{i}+t_{i}\right) x_{i j}+\alpha_{j}\left[u^{j}\left(x_{1 j}, x_{2 j}, \ldots, x_{n j}, z\right)-u^{{ }^{* j}}\right] \quad x_{i j} \geq 0
$$

Where $\alpha \mathrm{j}$ is a Lagrangian multiplier and pi is price of commodity i. We immediately obtain the Kuhn-Tucker conditions:

$$
\left\{\begin{array}{r}
p_{i}+t_{i}-\alpha_{j}\left(\frac{\partial \boldsymbol{u}^{j}}{\partial x_{i j}}+\frac{\partial \boldsymbol{u}^{j}}{\partial z} \frac{\partial z}{\partial x_{i j}}\right) \geq 0 \\
x_{i j}\left[p_{i}+t_{i}-\alpha_{j}\left(\frac{\partial \boldsymbol{u}^{j}}{\partial x_{i j}}+\frac{\partial \boldsymbol{u}^{j}}{\partial z} \frac{\partial z}{\partial x_{i j}}\right)\right]=0
\end{array}\right.
$$

Similarly the goal of the (competitive)firm is taken to be maximization of the profits subject to the constraint given by its production relation $f^{k}() \leq$.0 , Its Lagrange function is as follows: $\mathrm{L}_{\mathrm{k}}=\sum_{i=1}^{n} p_{i} y_{i k}-\beta_{k} f^{k}($.

The Kuhn - Tucker condition is as follows: $p_{i}-\beta_{k} \frac{\partial f^{k}}{\partial y_{i k}} \geq 0$

\section{Pareto Optimal the Price-Taxes Solution}

Our objective now is to determine what value of taxes will induce consumers and firms to select Pareto-optimal activity level under sustainable condition of ecological resources. That is, we want to know what tax structure can sustain a competitive equilibrium that is Pareto-optimal. This can be achieved by setting $p \mathrm{i}=\omega \mathrm{i}, \mu \mathrm{k}=\beta \mathrm{k}$ and $\alpha \mathrm{j}=\lambda \mathrm{j}, t_{i}=\delta \frac{\partial S(.)}{\partial x_{i j}}$. Note that competitive equilibrium is characterized by condition (7) and (9), and the Pareto-optimal under sustainable condition of ecological resources is characterized by condition (5) and (6).

By comparing condition (6) and (9), we can find that condition (6) and (9) are exactly the same if there are $\mathrm{pi}=\omega \mathrm{i}$ and $\mu \mathrm{k}=\beta \mathrm{k}$. Similarly, by comparing condition (5) and (7), we can also see that condition (5) is identical with condition (6) if there are $\alpha \mathrm{j}=\lambda \mathrm{j}$ and $t_{i}=\delta \frac{\partial S(.)}{\partial x_{i j}}$.Thus these systems will have the same solution if they are unique. Proposition: Given the assumed concave and convex conditions, Pareto optimal tax rate in the perfectly competitive market with sustainable condition of ecological resources is $t_{i}=\delta \frac{\partial S(.)}{\partial x_{i j}}$. We can see from the expression of the tax rate. The size of the tax rate depends on $\delta$ and the rate of pollution generated by the consumption: $\frac{\partial S(.)}{\partial x_{i j}}$ ;i.e.Marginal pollution. $\delta$ Is the coefficient of sustainable condition of ecological resources in Lagrange function. It means the increase in the utility function produced by adding one unit of natural resources, Namely the shadow price of 
ecological resources. It shows that the size of the tax rate depends on the shadow price of natural ecological resources and the marginal pollution rate.

\section{References}

[1] William J.Baumol, and Wallace E. Oates, The Theory of Environmental Policy[M]. second edition,Cambridge University Press 1988, P36-48.

[2] Howarth , R, B, and R, B. Norgaard(1992),Environmental Valuation under Sustainable Development, American Economic Review, 82(2), 473-7,1992

[3] Solow, R.M,The economics of resources or the resources of economics, American Economic review,64,1-14,1974.

[4] Hartwick, J. M, Intergenerational equity and the inverting of rent from exhaustible resources, American Economic Review,67 ( 5) 972-4,1977.

[5] Solow, R.M,On the intertemporal allocation of natural resources, Scandinavian Jounral of Economics,88,141-9,1986. 